\title{
Exploring Rural Family Physicians' Challenges in Providing Dementia Care: A Qualitative Study*
}

\author{
Adina Constantinescu, ${ }^{1}$ Hui Li, ${ }^{1}$ Jennifer Yu, ${ }^{1}$ Cassandra Hoggard, ${ }^{1}$ and Jayna Holroyd-Leduc ${ }^{2}$
}

\begin{abstract}
RÉSUMÉ
Cinq cent soixante-quatre mille Canadiens sont actuellement atteints de démence. Ce nombre continuera de s'accroître avec le vieillissement de la population. Les médecins de famille jouent un rôle important dans le diagnostic et la gestion des patients avec démence. Bien que des recherches aient montré les perspectives des médecins de famille dans les soins liés à la démence en milieu urbain, les connaissances associées aux défis dans les régions rurales sont encore très limitées. Cette étude visait à explorer les expériences des médecins de famille qui dispensent des soins à des patients avec démence dans des régions rurales en Alberta (Canada). Trois groupes de discussion semi-structurés comprenant 16 médecins de famille ont été organisés afin d'évaluer les barrières et les facilitateurs dans la prestation de soins à des personnes avec démence de trois communautés rurales. Les questions des groupes de discussion ont été élaborées selon le modèle du Theoretical Domains Framework (TDF) et ont été analysées selon cette approche-cadre. Les compétences des médecins, leurs opportunités et leur motivation semblent jouer des rôles majeurs dans les soins destinés à ces patients. Ces résultats de recherche pourraient être utilisés pour améliorer la qualité des soins en milieu rural pour les patients atteints de démence.
\end{abstract}

\begin{abstract}
Currently, 564,000 Canadians are living with dementia. This number will continue to rise as the population ages. Family physicians play an integral role in the diagnosis and management of dementia patients. Although studies have looked at family physician perspectives on dementia care in the urban setting, much less is known about challenges in rural areas. This study aimed to explore rural family physicians' experiences in caring for patients with dementia in rural Alberta, Canada. We conducted three semi-structured focus groups with 16 family physicians to evaluate barriers and facilitators to providing care to persons with dementia in three rural communities. We developed focus group questions based on the theoretical domains framework (TDF) and analysed them using a framework approach. Physician capabilities, opportunities, and motivations appear to play important roles in caring for these patients. These research findings can be used to advance quality of care for rural dementia patients.
\end{abstract}

1 Family Medicine Program, University of Calgary

2 Departments of Medicine and Community Health Sciences, University of Calgary

* We thank Grace Perez and Nathan Turley at the University of Calgary Family Medicine Research Office for their valuable support and guidance throughout this project. We also thank the physicians who participated in focus group discussions in Airdrie, Okotoks, and Black Diamond, Alberta.

Manuscript received: / manuscrit reçu : 02/01/17

Manuscript accepted: / manuscrit accepté : 19/01/18

Mots-clés : vieillissement, médecine familiale, médecine générale/ soins de première ligne, démence, médecine en milieu rural, gériatrie/ soins aux personnes âgées, médecine fondée sur des données probantes

Keywords: aging, family practice/general practice/primary care, dementia, rural medicine, geriatric/care of the elderly, evidence-based medicine

La correspondance et les demandes de tirés-à-part doivent être adressées à : / Correspondence and requests for offprints should be sent to:

Adina Constantinescu, M.D., CCFP, CoE

Family Medicine Program

University of Calgary

201726 Ave. SW

Calgary, AB T2T1E5

<amconsta@ucalgary.ca> 
The number of Canadians currently living with dementia is 564,000 , a number that is expected to almost double in the next 15 years (Alzheimer Society of Canada, 2017). Dementia affects not only the individual but also families and caregivers (Brodaty \& Donkin, 2009). Family physicians play an integral role in the diagnosis and management for patients with dementia. Accordingly, Canadian family physicians should be able to assess cognitive impairment in keeping with recommendations (Patterson et al., 2001).

Pimlott et al. (2009a) found that family physicians in Calgary, Toronto, and Ottawa were minimally aware of the recommendations of the Canadian Consensus Conference on the Diagnosis and Treatment of Dementia (Gauthier et al., 2012). An earlier study showed that there was also an over-reliance on diagnostic imaging for diagnosis (Pimlott et al., 2006). Eighty-two per cent of patients with suspected or confirmed dementia were referred to a specialist, suggesting a lack of comfort among family physicians with diagnosis and management in urban Canada (Pimlott et al., 2006).

The challenges faced by family physicians are not unique to Canada. A study in Scotland found that one third of family physicians expressed limited confidence in their diagnostic skills and two thirds lacked confidence in dementia management (Turner et al., 2004). In an American study, dementia was ranked within the top three geriatric mental health problems (Williams \& Connolly, 1990). Family physicians in the Netherlands appropriately selected patients for specialist referral, but had decreased accuracy in differentiating between dementia types (van Hout, Vernooij-Dassen, Poels, Hoefnagels, \& Grol, 2000).

Considering the evidence that dementia is not optimally diagnosed in primary care, it is not surprising that many studies have focused on barriers to dementia diagnosis; fewer studies have looked at the challenges faced by primary care physicians in dementia management. Diagnostic uncertainty and dementia complexity have been identified as barriers by urban family physicians, whereas physicians viewed time, patient's family members, and physician familiarity with patients as both barriers and enablers (Pimlott et al., 2009b). An American study found that family physician failure to recognize dementia symptoms, negative attitudes, and lack of time were the main barriers to care (Stewart et al., 2014). Factors affecting diagnosis and delivery of dementia care include patient behavior challenges, comorbidities, caregiver challenges, and structural barriers such as clinician time (Stewart et al., 2014).

Although studies have examined family physician perspectives on dementia care in the urban setting, very little is known about challenges faced in rural Canada. In comparison to their urban counterparts, rural family physicians often work in geographically isolated clinics with limited access to specialists, support services, and diagnostic tools (Greenway-Crombie, Snow, Disler, Davis, \& Pond, 2012; Koller et al., 2010). Growing dementia prevalence may be felt more keenly in aging rural communities facing physician shortages. It is important, therefore, to explore the types of challenges that rural physicians face with respect to dementia care in hopes of discovering new improvement opportunities.

Our aim in this study was to explore rural family physicians' experiences in caring for patients with dementia. We specifically explored barriers and facilitators to care in rural family practices.

\section{Methods}

Study Design

We conducted semi-structured qualitative focus groups to evaluate barriers and facilitators in providing care to persons with dementia in rural family practice. This method applies the cumulative wisdom of a group and has been effectively used in several other research studies evaluating physician attitudes, values, and opinions regarding a particular issue in an open, shared setting (Kitzinger, 2005). Our focus group participants were all family physicians, and the questions did not target specific individual practice issues but focused on general barriers or facilitators to dementia care in rural communities; therefore, we felt that individuals would be more likely to contribute. We selected three Southern Alberta rural family practices in Airdrie (population: 43,000), Black Diamond (population: 2,300), and Okotoks (population: 25,000). This was a resident physician-run project. We used convenience sampling to select these sites, all of which served an aging rural population that includes surrounding farms and ranches and, for the most part, did not have specialist supports within their communities to help manage dementia care. We targeted a clinic with five or more physicians at each site. Clinics were contacted by phone, and authors spoke with one physician on duty. The project was explained and that physician then acted as a liaison to recruit others at the site. We provided an information pamphlet via email to the liaison physician for further distribution, and we obtained signed consent from participating physicians on the focus group day.

Two researchers were present at each focus group, one to moderate the discussion and the other to take field notes. We developed focus group questions to identify possible barriers and facilitators of providing dementia care in rural family practices based on the theoretical domains framework (TDF; Cane, O'Connor, \& Michie, 2012). The TDF is a validated framework that, with a consensus approach, lets researchers categorize applicable psychological theories into one or more of 14 theoretical 
domains (Michie et al., 2005). (For more information, see Appendix 1). We audiotaped focus groups and an independent, contracted third party transcribed the audiotapes verbatim. Each reviewer individually read through the transcript and extracted themes on the basis of the TDF framework. The three reviewers (AC, HL, and JY) then met to reach a consensus on themes. In the event of a disagreement, they consulted a fourth reviewer (JHL).

Inclusion criteria for participants were family physicians working within one of the identified rural family practices and who provided care to seniors with dementia. We collected demographics from the participants, including age (range), gender, and number of years in practice. We gave participants written information about the study prior to their participating in the focus groups and obtained their informed written consent. This study received approval from the University of Calgary Conjoint Health Research Ethics Board.

\section{Data Analysis}

We applied a framework approach for analysis (Gale, Heath, Cameron, Rashid, \& Redwood, 2013; Pope, Ziebland, \& Mays, 2000). This approach is a form of content analysis that involves summarizing and classifying data within a thematic framework (Green \& Thorogood, 2014). Three researchers (AD, HL, JY) completed this process.

We categorized the themes gathered from the focus groups according to the theoretical domains framework (TDF) and the capability, opportunity, and motivational (COMB) system from the behaviour change wheel (BCW) model for identification of potential barriers and facilitators to clinical practice change (Cane et al., 2012; Michie, Johnston, Francis, Hardeman, \& Eccles, 2008). For a depiction of the mapping of the TDF and its domains, please refer to Appendix 2 (adapted from Cane et al., 2012).

The TDF is a validated framework that, with a consensus approach, lets researchers categorize applicable psychological theories into one or more of 14 theoretical domains (Michie et al., 2005). These domains do not identify the cause or explain behaviours, but are a guide to relevant explanations of behaviours and prompts to behaviour change (Michie et al., 2005). Building on this, Michie et al. then developed the behaviour change wheel $(2005 ; 2011)$. The premise of the wheel is that, to improve evidence-based practice, we need to first understand the behaviour and then target change interventions towards achieving that behaviour (Michie et al., 2011). The behaviour change wheel comprises three behaviour categories - capability, opportunity, and motivation, or COM-B - that correlate with intervention functions for behaviour change which can be used to affect policy (Michie et al., 2011). The 14 domains within the TDF can be mapped to the COM-B sub-categories.
We included additional codes that do not readily fit into the TDF to avoid exclusion of potentially relevant data or outliers. Saturation was reached when reviewers were unable to identify new themes.

\section{Results}

Demographics

Sixteen family physicians from the three Southern Alberta rural communities participated in the focus groups (Table 1). The majority of the participants were male $(75 \%)$ and 62.5 per cent were $41-50$ years of age. All participants had been in clinical practice 10 years or longer; all of them worked in a clinic with five or more family physicians. Eleven of the 16 participants $(68.8 \%)$ estimated that less than five per cent of their patient population had dementia.

Table 1: Demographics of focus group participants from the Airdrie, Black Diamond, and Okotoks communities in Alberta

\begin{tabular}{|c|c|}
\hline Age of Participants & $\begin{array}{l}\text { Number of } \\
\text { Participants }\end{array}$ \\
\hline Under 30 years & 0 \\
\hline $36-40$ years & 1 \\
\hline $41-45$ years & 5 \\
\hline $46-50$ years & 5 \\
\hline $51-55$ years & 0 \\
\hline $56-60$ years & 3 \\
\hline over 60 years & 2 \\
\hline \multicolumn{2}{|l|}{ Gender of Participants } \\
\hline Male & 12 \\
\hline Female & 4 \\
\hline \multicolumn{2}{|l|}{ Years since Medical School Graduation } \\
\hline Fewer than 10 years & 0 \\
\hline $10-20$ years & 6 \\
\hline Over 20 years & 10 \\
\hline \multicolumn{2}{|l|}{ Practice Setting } \\
\hline Group practice with 5 or more physicians & 16 \\
\hline Group practice with fewer than 5 physicians & 0 \\
\hline Solo practice & 0 \\
\hline \multicolumn{2}{|l|}{ Weekly Patient Care Hours* } \\
\hline Fewer than 20 hours & 1 \\
\hline $20-40$ hours & 6 \\
\hline $40-60$ hours & 8 \\
\hline Over 60 hours & 0 \\
\hline \multicolumn{2}{|l|}{ Percentage of Patient Population Older than 65} \\
\hline Less than $25 \%$ & 4 \\
\hline $25-50 \%$ & 10 \\
\hline $50-75 \%$ & 2 \\
\hline Over $75 \%$ & 0 \\
\hline \multicolumn{2}{|c|}{ Percentage of Patient Population with Dementia } \\
\hline Less than $5 \%$ & 11 \\
\hline $5-10 \%$ & 4 \\
\hline $11-20 \%$ & 1 \\
\hline $21-40 \%$ & 0 \\
\hline $41-60 \%$ & 0 \\
\hline Over $60 \%$ & 0 \\
\hline
\end{tabular}

* missing this data point from one participant 


\section{Thematic Results based on TDF Framework}

We categorized the themes gathered from the three focus groups under three COM-B components, which we classified into six sub-categories (Appendix 2) for mapping to a possible 14 domains. We identified themes fitting under nine out of the 14 TDF domains. Each theme was further mapped as either a barrier or a facilitator in the care of patients with dementia in rural Southern Alberta. We reached theme saturation after analysis of the third focus group.

\section{CAPABILITY COM-B COMPONENT}

We identified themes under the Psychological COMB Subcategory but none under the Physical COM-B Subcategory (Table 2).

Psychological COM-B Subcategory: Knowledge Domain. Rural family physicians identified limitations in their knowledge as a barrier to caring for patients with dementia. They cited lack of experience, lack of training, and a lack of understanding of the placement process. In addition, some expressed lack of knowledge on when to use certain investigations such as a computed tomography (CT) scan. A physician also realized diagnostic uncertainty and observed, "I find it sometimes hard to distinguish between [...] old-timer's and Alzheimer's".
Psychological COM-B Subcategory: Skills Domain. Skills refers to physicians' clinical reasoning skills, competencies, abilities, or clinical acumen when working with patients with dementia. The physicians felt that screening in the office can sometimes pick up dementia symptoms (screening would thus be a facilitator). However, others felt they can be "complex and the challenge is it's time-consuming" (screening, in this case, would be a barrier). They perceived dementia care as an area that requires further training "Because I don't have training in [...] dementia care and geriatric care - I know the basics."

Psychological COM-B Subcategory: Memory, Attention, $\mathcal{E}$ Decision Processes Domain. Physicians identified how the variability and complexity of dementia were barriers: "[Dementia] dynamically changes on a weekto-week basis and sometimes it's hard to make the connection or the diagnosis." As well, complicated comorbid conditions that sometimes accompany dementia created further barriers.

\section{OPPORTUNITY COM-B COMPONENT}

We were able to identify both facilitators and barriers within domains of the Physical and Social sub-categories (Table 3).

Table 2: Themes identified under the COM-B Component of Capability

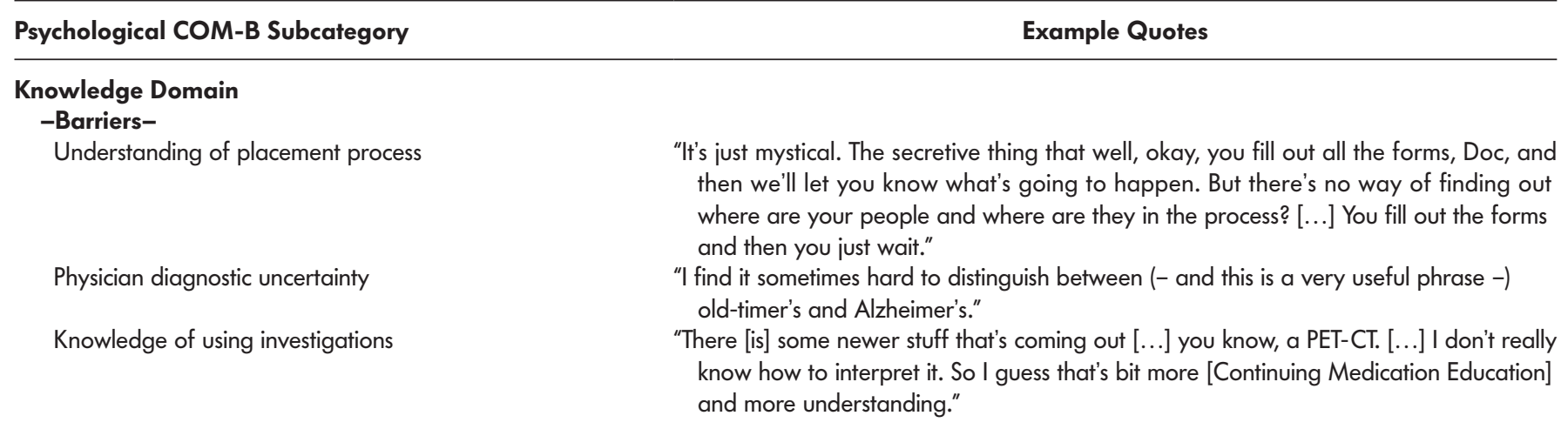

Skills Domain

-Facilitators-

Screening tools

-Barriers-

Screening tools

Physician experience
"We do some screenings; we may pick up on some of [dementia symptoms]."

"In regards to these screening tools, [for dementia, there are some good screen tools available, but they get complex, and the challenge is it's time-consuming."

"Because I don't have training in [you know] dementia care and geriatric care - I know the basics."

\author{
Memory Attention \& Decision Processes Domain \\ -Barriers- \\ Dementia variability/complexity \\ Complicated co-morbid conditions
}

"[Dementia, it's a moving target. It dynamically changes on a week-to-week basis and
sometimes it's hard to make the connection or the diagnosis."
"A lot of patients have complicated co-morbid conditions which actually aggravates
their dementia care." 
Table 3: Themes identified under the COM-B Component of Opportunity

\begin{tabular}{|c|c|}
\hline Physical COM-B Subcategory & Example Quotes \\
\hline \multicolumn{2}{|c|}{ Environmental Context \& Resources Domain } \\
\hline \multicolumn{2}{|c|}{-Facilitators- } \\
\hline Community resources & $\begin{array}{l}\text { "We know the home care nurses, we have a fairly good communication aligned with our homecare } \\
\text { nurses to sort of assess what the home environment is like." }\end{array}$ \\
\hline \multirow[t]{3}{*}{ Community resources } & $\begin{array}{l}\text { "So husband has dementia, gets placed in [supported living]. The wife now has to do this driving back } \\
\text { and forth [...], so transportation is a big issue." }\end{array}$ \\
\hline & $\begin{array}{l}\text { "[Occupational Therapy] assessment is [...] very good but they're not easy to get and there's not a } \\
\text { quick turnaround to help with that, to help with the diagnosis." }\end{array}$ \\
\hline & $\begin{array}{l}\text { "There is lack of support in the community in general where they live and access to certain living } \\
\text { circumstances or supportive living." } \\
\text { "Our health services is so [financially] pitiful for doing a house call as a physician, it acts as a disincentive." }\end{array}$ \\
\hline \multirow[t]{2}{*}{ Physician resources } & $\begin{array}{l}\text { "It takes many visits first with family and then with the patient, then with family again, }[\ldots] \text { and again } \\
\text { until they found something and they tend to come to you with stuff that you can't always solve. } \\
\text { [...] So it is very, very time-consuming, you know". }\end{array}$ \\
\hline & $\begin{array}{l}\text { "You don't make a diagnosis and go through all the implications in a } 15 \text { to } 20 \text { minute - it's not a } \\
15 \text { - to } 20 \text {-minute visit." }\end{array}$ \\
\hline Dementia Management & $\begin{array}{l}\text { "I don't think the medication is very effective. I find that even if we start patients on medications in } \\
\text { some circumstances, it doesn't really slow down the progression of the disease significantly, and } \\
\text { patients are frustrated because they're coming for [a] miracle cure." }\end{array}$ \\
\hline
\end{tabular}

\section{Social COM-B Subcategory}

\section{Social Influences Domain}

-Facilitators-

Community relationships

Physician relationships

\section{-Barriers-}

Family/caregiver stress

Family expectations
"[O]ften there will be neighbours that will look in, because they know their neighbours."

"Working in this practice my skills are enhanced because l'm supported by exceptional colleagues, and exceptional office system, which is very patient friendly, and [...] collegiality where we bounce ideas with each other in corridors. [E]ven the ability to ask for a second opinion."

"For a lot [caregivers] it's frustrating. It's difficult. A lot of them get burnt out and they think it's their duty to look after their demented spouse at home. [l]t's really hard on their health....and they get really run down."

"These patients are wandering and [the family has] nowhere [...] to go and then they come to you like you can fix it - you can't. A lot of it is counselling, a lot of it is just hand-holding. [T] hese people are frustrated."

"I'll also mention sometimes unrealistic expectations from relatives, from family. Especially [...] family who isn't around and shows up and thinks things should be done differently and that you are wrong."
Physical COM-B Subcategory: Environmental Context $\mathcal{E}$ Resources Domain. Geography and community resources were identified as both barriers and facilitators. On the positive end, "[In] rural [areas], when the resources are available, we tend to know the people [with suspected dementia] that we need to tap on the shoulder to bring in [...] and talk to." "We [also] know the home care nurses ... [and] have ... fairly good communication aligned with our homecare nurses to sort of assess what the home environment is like." Geography as a barrier occurs when patients in rural and isolated communities become reluctant to move out of their community to pursue further care in an urban setting, as the distance results in patients being farther away from their family.

Themes regarding community resources mapped as both facilitators and barriers. Some physicians felt that there was good access to multidisciplinary teams, labs, and investigations. However, other physicians felt that 
there was a lack of other community resources, such as access to a multidisciplinary team, occupational therapy assessments, mental health services, home care, or respite care for families. Physicians also cited inappropriate wait times for long-term care or assisted living, as well as wait times for a geriatric specialist.

Further barriers within the environmental context included physician resources such as time and money. The lack of monetary compensation for a rural physician to make house calls, as well as the perceived lack of effectiveness of medications for dementia, were barriers for busy rural physicians caring for patients with dementia.

Social COM-B Subcategory: Social Influences Domain. The close community relationships and the collegiality between physicians help rural physicians care for patients with dementia. Within a smaller community, "[o]ften there will be neighbours that will look in, because they know their neighbours."

Outside influences from the caregivers and different family expectations sometimes hindered the physician's ability to care for patients with dementia. For example, there were "sometimes unrealistic expectations from relatives, from family. Especially [...] family who isn't around and shows up and thinks things should be done differently and that you are wrong."

\section{MOTIVATION COM-B COMPONENT}

Motivation can be categorized into Reflective and Automatic COM-B sub-categories (Table 4). What motivates us to change can be our own instinctive thoughts (Automatic) or more contemplative thoughts (Reflective) (Michie et al., 2011).

Reflective COM-B Subcategory: Beliefs about Capabilities Domain. Some physicians cited that their own lack of confidence in diagnosis and management was a barrier for caring for patients with dementia. They commented that they "sometimes delay in making the diagnosis because [they] don't have a clue what to do."

Reflective COM-B Subcategory: Beliefs about Consequences Domain. Diagnostic implications were mapped as being both a barrier and facilitator for caring for patients with dementia in rural settings. In making the diagnosis of dementia for patients, physicians felt that an early diagnosis could potentially help the individual and family to make plans, thereby facilitating the care for these patients. On the other hand, making a diagnosis can be emotionally difficult for patients and their families, thereby hindering the process of dementia care.

Automatic COM-B Subcategory: Social, Professional Role E Identity Domain. Rural physicians felt that it was often their role to care for patients with dementia in their community; therefore, this was a facilitating theme.
Some comments suggested that "[Practicing rurally] you can't drop the ball. You can't say 'well, I'll see that part of town, but not the other.'"

Automatic COM-B Subcategory: Emotion Domain. Many physicians found it a relief to support these patients through their disease, and also rewarding to provide care for them and their families. For example, one physician commented, "But I think once it's been said and you can actually go, 'Okay now we have a plan,' then things get better." On the other hand, some physicians also commented on how caring for patients with dementia can produce negative emotions that are barriers to dementia care. Physicians identified emotions such as frustration, distress, and stress responding to patient behaviours. Some physicians felt that it was emotionally draining.

\section{Discussion}

Researchers have conducted a few urban studies with focus groups to understand the challenges that family physicians face in providing dementia care (Pimlott et al., 2009; Turner et al., 2004). To our knowledge, this is one of the first studies to explore the barriers and facilitators of dementia care as perceived by physicians in rural Canada. Family physicians in rural areas are often tasked with the unique role of managing dementia without access to specialist services. Our findings demonstrate that components such as physician capabilities, opportunities, and motivations play important roles in physicians' caring for these patients (Michie, Johnston, Francis, Hardeman, \& Eccles, 2008).

Physicians outlined multiple barriers with respect to their own knowledge in caring for dementia patients. Since dementia patients likely make up a minority of a rural physician's patient panel, it is not surprising that physicians have limited experience with dementia diagnosis and management. This perceived lack of knowledge in diagnosing dementia is not unique to rural physicians but applies to urban physicians as well (Pimlott et al., 2009; van Hout et al., 2000; Woods et al., 2003). Based on previous studies, physicians are not alone in feeling uncertain about knowledge and the lack of dementia information. In rural southwest Ontario, Forbes et al. (2012) explored the barriers and facilitators faced by caregivers, health care practitioners, and persons with dementia in accessing dementia information. They found that a lack of community services and supports, poor integration of existing supports, and decreased care partner involvement were barriers. Facilitators included establishing trust between families, patients, and health care providers, and having a structured knowledge exchange format. 
Table 4: Themes identified under the COM-B Component of Motivation

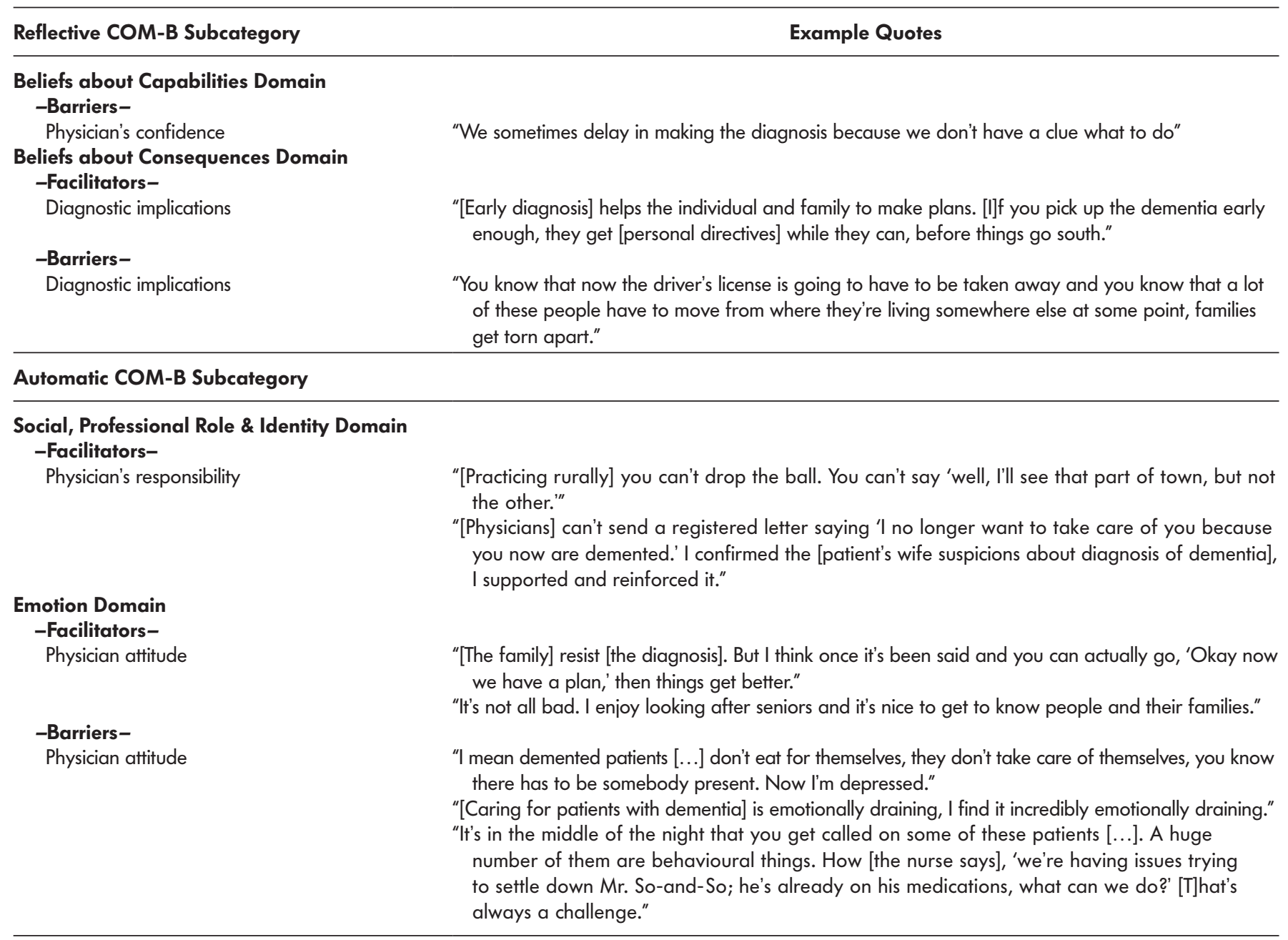

Screening tools were seen as helpful in allowing for an earlier diagnosis, but some physicians reported them to be confusing and time-consuming. Dementia diagnostic and functional assessment tools are underused, which may in part be explained by these time constraints and limited experience (Parmar et al., 2014).

In regards to environmental context, geography was identified as both a facilitator and a barrier to care. Rural physicians often have the opportunity for closer relationships with patients, making dementia symptom surveillance more tangible. Developing trusting relationships between health care providers and patients is an important cornerstone in rural medicine (Pomerantz, 2009). Physicians also identified their community and colleague relationships as facilitators of dementia care. Our study found that physicians value community supports in dementia care, which mirrors findings from a rural northern Ontario study. Wiersma and Denton (2013) observed that social networks and community supports like neighbours, volunteers, and community leaders offered a safety net and preserved independence for persons living with dementia.

Conversely, geographic isolation means limited access to care facilities and geriatric specialists, and it can make rural physician home visits more difficult. Important resources, such as CT scans and transport services for patients with disabilities, are often not available. Despite these limitations, some rural physicians felt that the local resources they did have, such as home care, were accessible and of good quality.

Rural family doctors also reported significant time constraints resulting from the other demands of their practice. Prolonged wait times for specialists was a barrier, which contributed to patients with dementia having to be cared for locally with limited resources while awaiting specialist assessments. However, the issue of long wait times is an issue across Canada and is not particularly unique to rural communities (Barua, 2015).

Family and caregiver stress and expectations were described as barriers. Physicians expressed concerns in 
regards to caregiver burden in these rural communities. In the absence of local facilities to care for dementia patients, family became the default caregiver $(\mathrm{Wu}$, Gao, Chen, \& Dong, 2016). Our results are supported by other studies that have explored the caregiver perspective. A rural study found that 31 per cent of family caregivers were not satisfied with received care (Dal Bello-Haas, Cammer, Morgan, Stewart, \& Kosteniuk, 2014). In a systematic review focusing on rural dementia care in Canada from a caregiving perspective, it was suggested that more research is needed to reduce caregiver strain and a need to expand the caregiving role beyond the primary caregiver (Innes, Morgan, \& Kostineuk, 2011). The review also suggested that more public awareness of dementia and caregiver impact is needed, as is increased accessibility to services (Innes, Morgan, \& Kostineuk, 2011). Caregiver education and support is also needed and has positive effects on quality of life when implemented in remote communities (Innes, Morgan, \& Kostineuk, 2011).

Physicians evidenced a lack of faith in current dementia management medications, which do not always guarantee symptom improvement. Current dementia medications, such as cholinesterase inhibitors, produce only small short-lived improvements for mild to moderate dementia but do not always translate into clinically meaningful effects (Buckley \& Salpeter, 2015).

The difficulties identified with dementia management in this study have been described previously (Williams \& Connolly, 1990); however, the difficulties may be compounded by a lack of resources and fewer specialist supports in rural areas (Greenway-Crombie et al., 2012). Nonetheless, social and professional roles and responsibilities act as motivators in caring for these patients. Overall, physicians agreed that caring for patients with dementia, although at times emotionally taxing, was rewarding work.

\section{Study Strengths and Limitations}

This study included focus groups within three rural communities of varying sizes and proximities to an urban center. We feel the findings are transferrable to other small Canadian communities given that we reached theme saturation. However, the extent to which we identified barriers and facilitators representative of more remote communities and single-practitioner practices is unclear.

Physicians in our focus group perceived a lack of resources in their communities. There may be a discrepancy between physician-perceived lack of resources and the actual lack of resources as suggested in previous research (Herron, Rosenberg, \& Skinner, 2016). Although it was beyond the scope of this project to evaluate actual physicians' knowledge of resources, this knowledge could be explored in future research.

\section{Future Directions and Implications}

Findings from this research can be used in multiple ways to advance the delivery and quality of care for rural patients with dementia. With the results of our study, the themes gathered could be used to develop interventions and policies targeted at specific behavior changes from the behaviour change wheel. In addition to supporting family physicians in obtaining needed knowledge and skills, evaluation of formalized multidisciplinary team-based care models in rural settings could be explored. Additionally, physicians experienced in dementia care (including Care of the Elderly practitioners) should be encouraged to practice in rural communities to provide support to family physicians as both consultants and mentors.

\section{Conclusion}

As the primary health care providers for many patients with dementia, rural family physicians are faced with many challenges. As the population ages, particularly in rural Canada, the prevalence of dementia and impact on rural physicians is projected to increase substantially. Several barriers related to capability, opportunity, and motivation must be addressed in order to help rural family physicians provide the needed care to those with dementia.

\section{Supplementary Material}

To view supplementary material for this article, please visit https:/ / doi.org/10.1017/S0714980818000417

\section{References}

Alzheimer Society of Canada. (2017). Dementia numbers in Canada. Retrieved from http:/ / www.alzheimer.ca/en/ About-dementia/What-is-dementia/Dementia-numbers

Barua, B. (2015). Waiting your turn: Wait times for health care in Canada, 2015 Report. Retrieved from https: / / www. fraserinstitute.org/studies/waiting-your-turn-waittimes-for-health-care-in-canada-2015-report

Brodaty, H., \& Donkin, M. (2009). Family caregivers of people with dementia. Dialogues in Clinical Neuroscience, 11(2), 217-228.

Buckley, J. S., \& Salpeter, S. R. (2015). A risk-benefit assessment of dementia medications: Systematic review of the evidence. Drugs \& Aging, 32(6), 453-467. doi:10.1007/ s40266-015-0266-9

Cane, J., O'Connor, D., \& Michie, S. (2012). Validation of the theoretical domains framework for use in behaviour change and implementation research. Implementation Science 7(1), 37. doi:10.1186/1748-5908-7-37 
Dal Bello-Haas, V. P. M., Cammer, A., Morgan, D., Stewart, N., \& Kosteniuk, J. (2014). Rural and remote dementia care challenges and needs: Perspectives of formal and informal care providers residing in Saskatchewan, Canada. Rural and Remote Health, 14(3), 2747.

Forbes, D. A., Finkelstein, S., Blake, C. M., Gibson, M., Morgan, D. G., Markle-Reid, M., ... Thiessen, E. (2012). Knowledge exchange throughout the dementia care journey by Canadian rural community-based health care practitioners, persons with dementia, and their care partners: An interpretive descriptive study. Rural and Remote Health, 12(4), 2201.

Gale, N. K., Heath, G., Cameron, E., Rashid, S., \& Redwood, S. (2013). Using the framework method for the analysis of qualitative data in multi-disciplinary health research. BMC Medical Research Methodology, 13, 117. doi:10.1186/1471-2288-13-117

Gauthier, S., Patterson, C., Chertkow, H., Gordon, M., Herrmann, N., Rockwood, K., ... Soucy, J. (2012). Recommendations of the 4 th Canadian Consensus Conference on the diagnosis and treatment of dementia (CCCDTD4). Canadian Geriatrics Journal, 15(4), 120-126.

Green, J., \& Thorogood, N. (2014). Qualitative methods for health research (3rd ed.). Thousand Oaks, CA: Sage.

Greenway-Crombie, A., Snow, P., Disler, P., Davis, S., \& Pond, D. (2012). Influence of rurality on diagnosing dementia in Australian general practice. Australian Journal of Primary Health, 18(3), 178-184. doi:10.1071/ PY12008

Herron, R., Rosenberg, M., \& Skinner, M. (2016). The dynamics of voluntarism in rural dementia care. Health $\mathcal{E}$ Place, 41, 34-41.

Innes, A., Morgan, D., \& Kostineuk, J. (2011). Dementia care in rural and remote settings: A systematic review of informal/family caregiving. Maturitas, 68, 34-46.

Kitzinger, J. (2005). Focus group research: Using group dynamics to explore perceptions, experiences and understandings. In I. Holloway (Ed.), Qualitative research in health care (pp. 56-70). Maidenhead, ENG: Open University Press.

Koller, D., Eisele, M., Kaduszkiewicz,H., Schön, G., Steinmann, S., Wiese, B., ... van den Bussche, H. (2010). Ambulatory health services utilization in patients with dementia-Is there an urban-rural difference? International Journal of Health Geographics, 9, 59. doi:10.1186/1476-072X-9-59

Michie, S., Johnston, M., Abraham, C., Lawton, R., Parker, D., \& Walker, A. (2005). Making psychological theory useful for implementing evidence based practice: A consensus approach. Quality and Safety in Health Care, 14(1), 26-33. doi:10.1136/qshc.2004.011155

Michie, S., Johnston, M., Francis, J., Hardeman, W. \& Eccles, M. (2008). From theory to intervention: Mapping theoretically derived behavioural determinants to behaviour change techniques. Applied Psychology, 57, 660-680. doi:10.1111/j.1464-0597.2008.00341.x
Michie, S., van Stralen, M. M., \& West, R. (2011). The behaviour change wheel: A new method for characterising and designing behaviour change interventions. Implementation Science 6, 42. http:/ / doi.org/10.1186/1748-5908-6-42

Parmar, J., Dobbs, B., McKay, R., Kirwan, C., Cooper, T., Marin, A., \& Gupta, N. (2014). Diagnosis and management of dementia in primary care: Exploratory study. Canadian Family Physician Medecin De Famille Canadien, 60(5), 457-465.

Patterson, C., Grek, A., Gauthier, S., Bergman, H., Cohen, C., Feightner, J. W., ... Hogan, D. B. (2001). The recognition, assessment and management of dementing disorders: Conclusions from the Canadian Consensus Conference on Dementia. Canadian Journal of Neurological Sciences / Journal Canadien des Sciences Neurologiques, 28(S1), S3-S16.

Pimlott, N. J. G., Persaud, M., Drummond, N., Cohen, C. A., Silvius, J. L., Seigel, K., ... Dalziel, W. B. (2009a). Family physicians and dementia in Canada: Part 1. Clinical practice guidelines: Awareness, attitudes, and opinions. Canadian Family Physician / Medecin De Famille Canadien, 55(5), 506-7.e1-5.

Pimlott, N. J. G., Persaud, M., Drummond, N., Cohen, C. A., Silvius, J. L., Seigel, K., ... Dalziel, W. B. (2009b). Family physicians and dementia in Canada: Part 2. Understanding the challenges of dementia care. Canadian Family Physician / Medecin De Famille Canadien, 55(5), 508-9.e1-7.

Pimlott, N. J. G., Siegel, K., Persaud, M., Slaughter, S., Cohen, C., Hollingworth, G., ... Eliasziw, T. (2006). Management of dementia by family physicians in academic settings. Canadian Family Physician, 52(9), 1108-1109.

Pomerantz, A. (2009). Ethics conflicts in rural communities: Overlapping roles. In W. A. Nelson (Ed.), Handbook for rural healthcare ethics: A practical guide for professionals. Lebanon, NH: University Press of New England for Dartmouth College Press.

Pope, C., Ziebland, S., \& Mays, N. (2000). Qualitative research in health care. Analysing qualitative data. BMJ (Clinical Research Ed.), 320(7227), 114-116.

Stewart, T. V., Loskutova, N., Galliher, J. M., Warshaw, G. A., Coombs, L. J., Staton, E. W., ... Pace, W. D. (2014). Practice patterns, beliefs, and perceived barriers to care regarding dementia: A report from the American Academy of Family Physicians (AAFP) national research network. Journal of the American Board of Family Medicine: JABFM, 27(2), 275-283. doi:10.3122/jabfm.2014.02.120284

Turner, S., Iliffe, S., Downs, M., Wilcock, J., Bryans, M., Levin, E., ... O'Carroll, R. (2004). General practitioners' knowledge, confidence and attitudes in the diagnosis and management of dementia. Age and Ageing, 33(5), 461-467. doi:10.1093/ageing/afh140

Van Hout, H., Vernooij-Dassen, M., Poels, P., Hoefnagels, W., \& Grol, R. (2000). Are general practitioners able to accurately diagnose dementia and identify Alzheimer's disease? A comparison with an outpatient memory clinic. 
The British Journal of General Practice: The Journal of the Royal College of General Practitioners, 50(453), 311-312.

Wiersma, E. C., \& Denton, A. (2013). From social network to safety net: Dementia-friendly communities in rural northern Ontario. Dementia, 15(1), 51-68.

Williams, M. E., \& Connolly, N. K. (1990). What practicing physicians in North Carolina rate as their most challenging geriatric medicine concerns. Journal of the American Geriatrics Society, 38(11), 1230-1234.
Woods, R. T., Moniz-Cook, E., Iliffe, S., Campion, P., VernooijDassen, M., Zanetti, O., \& Franco, M. (2003). Dementia: Issues in early recognition and intervention in primary care. Journal of the Royal Society of Medicine, 96(7), 320-324.

Wu, C., Gao, L., Chen, S., \& Dong, H. (2016). Care services for elderly people with dementia in rural China: A case study. Bulletin of the World Health Organization, 94(3), 167-173. doi:10.2471/BLT.15.160929 